\title{
Impact of substance use on conversion to psychosis in youth at clinical high risk of psychosis
}

\author{
Lisa Buchy ${ }^{a}$, Diana Perkins ${ }^{b}$, Scott Woods $^{c}$, Lu Liua ${ }^{a}$, and Jean Addington ${ }^{a}$ \\ aHotchkiss Brain Institute, Department of Psychiatry, University of Calgary, Calgary, Alberta, \\ Canada \\ bepartment of Psychiatry, University of North Carolina, Chapel Hill NC \\ 'Department of Psychiatry, Yale University, New Haven CT
}

\begin{abstract}
Elevated rates of substance use (alcohol, tobacco, cannabis) have been reported in people at clinical high risk (CHR) of developing psychosis and there is some evidence that substance use may be higher in those who convert to a psychosis compared to non-converters. However little is known about the predictive value of substance use on risk of conversion to psychosis in those at CHR of psychosis. In the current study, 170 people at CHR of psychosis were assessed at baseline on severity of alcohol, tobacco and cannabis using the Alcohol and Drug Use Scale. Participants were recruited across three sites over a four year period as part of the Enhancing the Prospective Prediction of Psychosis (PREDICT) study. Predictors of conversion to psychosis were examined using Cox proportional hazards models. Results revealed that low use of alcohol, but neither cannabis use nor tobacco use at baseline contributed to the prediction of psychosis in the CHR sample. Prediction algorithms incorporating combinations of additional baseline variables known to be associated with psychotic conversion may result in increased predictive power compared with substance use alone.
\end{abstract}

\section{Keywords}

alcohol; cannabis; prodrome; psychosis; substance use; tobacco

\footnotetext{
(C) 2014 Elsevier B.V. All rights reserved.

"Corresponding Author: Dr. Jean Addington, Mathison Centre for Mental Health Research \& Education, University of Calgary, 3280 Hospital Drive NW, Calgary, Alberta T2N 4Z6 Canada. Phone: 403-210-6379; Fax: 403-210-9182; jmadding @ ucalgary.ca.

Publisher's Disclaimer: This This is a PDF file of an unedited manuscript that has been accepted for publication. As a service to our customers we are providing this early version of the manuscript. The manuscript will undergo copyediting, typesetting, and review of the resulting proof before it is published in its final citable form. Please note that during the production process errors may be discovered which could affect the content, and all legal disclaimers that apply to the journal pertain.

Conflict of Interest

All authors declare no conflict of interest.

Contributors

The first author wrote the first version of the manuscript and performed data analysis. The second and third authors assisted in data collection, and provided laboratory space and funding. The fourth author assisted in data organization and data analysis. The fifth author assisted in data collection, provided laboratory space and funding, and assisted in the writing of the final version of the manuscript.
} 


\section{Introduction}

In a recent review, Addington and colleagues (Addington et al., in press) identified ten studies that examined substance use in people who are at clinical high risk (CHR) of developing psychosis. Across these studies, the most commonly used substances were cannabis, alcohol and tobacco, with cannabis and tobacco use being higher than in healthy controls (Auther et al., 2012), and with rates similar to those experiencing a first-episode of psychosis (Barnett et al., 2007; Cooper et al., 2012; Sevy et al., 2001). Fewer studies have examined the relationship between substance use and conversion to psychosis in CHR. Cannon et al (Cannon et al., 2008) reported that a history of any substance abuse was one of five predictors of conversion to psychosis in a multivariate model. Kristensen and Cadenhead (Kristensen and Cadenhead, 2007 found that CHR individuals were more likely to develop psychosis within one year if they had used tobacco or met criteria for cannabis abuse/dependence. Several of the remaining studies examining substance use in those at CHR have reported no significant relationships between severity of use and later conversion to psychosis (Auther et al., 2012; Phillips et al., 2002; Ruhrmann et al., 2010; Thompson et al., 2011). However, some studies evaluated cannabis only (Korver et al., 2010), or recorded the use of any substance globally rather than multiple individual ones (Cannon et al., 2008; Thompson et al., 2011). In addition, it may be important to consider the role of positive symptoms as there is some evidence that cannabis use may be related to positive symptom severity (Corcoran et al., 2008; Korver et al., 2010). Furthermore, the negative studies may be underpowered to demonstrate a positive relation between substance use and conversion, or employed statistical tests insensitive to the predictive value of substance use for psychosis onset. As such, it is unclear whether there is an effect of substance use on conversion to psychosis in CHR individuals.

Therefore, the aim of the current prospective study was to examine in a large, well characterized sample of individuals at CHR of psychosis 1) severity of substance use at baseline in people who converted to a psychosis compared to non-converters over a four year period, and 2) the relationship between substance use at baseline and rate of conversion to psychosis.

\section{Materials and Methods}

\subsection{Sample}

One-hundred and seventy (96 males, 74 females) individuals at CHR of psychosis participated as part of a multi-site NIMH funded study "Enhancing the Prospective Prediction of Psychosis" (PREDICT). This was a 4-year longitudinal observational study to determine predictors of conversion to psychosis in individuals at CHR of developing psychosis who were not using anti-psychotic medication. The study was conducted at the Universities of Toronto, North Carolina, and Yale. All CHR individuals met the Criteria of Prodromal States (COPS) based on the Structured Interview for Prodromal Syndromes (SIPS) (McGlashan et al., 2010). One hundred sixty-seven CHR participants met attenuated positive symptom syndrome (APSS) criteria, which includes the emergence or worsening of a non-psychotic level disturbance in thought content, thought process or perceptual abnormality over the past year, six participants met criteria for genetic risk and deterioration 
(GRD), which required either a first degree relative with a psychotic disorder or the subject having schizotypal personality disorder plus at least a 30\% drop in functioning on the General Assessment of Functioning (GAF) scale in the past 12 months, and three participants met both APSS and GRD.

Participants were excluded if they met criteria for any current or lifetime axis I psychotic disorder, prior history of treatment with an antipsychotic, IQ<70, or past or current history of a clinically significant central nervous system disorder that may confound or contribute to clinical high risk symptoms, or using antipsychotics at baseline. Antipsychotics were not used at any later points in this study.

\subsection{Measures}

Criteria for a prodromal syndrome and for conversion to psychosis were determined using the SIPS (McGlashan et al., 2010). Conversion meant that at least one of the five attenuated positive symptoms reached a psychotic level of intensity (rated 6) for a frequency of $\geq 1$ hour/day for 4 days/week during the past month or that symptoms seriously impacted functioning (e.g. severely disorganized or dangerous to self or others). Symptoms were assessed with the Scale of Prodromal Symptoms (SOPS), which consists of 19 items in 4 symptom domains: positive, negative, general, and disorganized.

Participants were rated on substance use with a well-established rating scale, the Alcohol and Drug Use Scale (AUS/DUS) (Drake et al., 1996). The AUS/DUS was used to record severity of substance use within the past month. It is a 5-point scale with anchors that are equivalent to $1=$ abstinent, $2=$ use without impairment, $3=$ abuse, $4=$ dependence and $5=$ severe dependence. Ratings of 3 and 4 reflect behaviors equivalent to DSM-IV diagnoses of abuse and dependence. Severity ratings were recorded for alcohol, tobacco, cannabis, cocaine, opiates, PCP, amphetamine, MDMA, GHB, huffing, hallucinogens and other substances at baseline.

\subsection{Statistical Analysis}

Differences in baseline characteristics of converters vs non-converters were evaluated by either $t$-tests (continuous data), or $\chi^{2}$ or Fisher's Exact tests (categorical data). Pearson's rho was used to correlate substance use with age and symptom severity. Substance use variables were non-normally distributed and non-transformable; therefore, Mann Whitney U tests were used to compare substance use severity at baseline between groups. Cox proportional hazard regression models were used to estimate the association of substance use with conversion to psychosis. The assumption of proportionality was violated for ratings of tobacco use; therefore, ratings of 2-4 were combined as any use. The analysis of time to conversion was calculated in days since entry into the study. Follow-up for non-converters was calculated as the last date when SOPS ratings were acquired within 4 years. The effects of risk factors are described by their Cox regression hazard ratio (HR) and 95\% confidence intervals. We first considered a model which included all the predictors that had a p-value $<0.25$ in the univariate analyses, with an aim to drop the least significant variable, then continue by successively refitting the model and applying the same backward elimination 
rule until all remaining variables were statistically significant. Statistical analyses were conducted using SPSS 20.0 and SAS 3.0.

\subsection{Procedures}

All three sites involved in this longitudinal study of predictors of conversion to psychosis recruited CHR individuals. Raters were experienced research clinicians who demonstrated adequate reliability at routine reliability checks. Gold standard post-training agreement on the critical threshold for determining initial eligibility and subsequent conversion status based on the SIPS was excellent (kappa=.90). The PI or clinical psychiatrist or psychologist at each site conducted a comprehensive clinical assessment to determine if entry criteria were met. JA chaired weekly conference calls to review criteria for all individuals admitted to the study. The study protocols and informed consents were reviewed and approved by the ethical review boards of all three study sites. AUS/DUS ratings were acquired at the baseline assessment.

\section{Results}

\subsection{Demographics}

The mean age of the sample was 19.7 years $(\mathrm{SD}=4.5)$. Demographic characteristics are shown in Table 1. Converters and non-converters did not significantly differ on age, $t=0.19$, $\mathrm{p}=0.90$, gender, $\chi^{2}=1.08, \mathrm{p}=0.30$, race, $\mathrm{p}=0.32$, marital status, $\mathrm{p}=0.47$, or education, $\mathrm{p}=0.41$.

The use of substances other than alcohol, tobacco or cannabis was either minimal or absent, therefore the use of these substances were not considered further in relation to demographic variables, positive symptoms, or rate of conversion to psychosis. Age was significantly associated with use of tobacco, $r=0.24, p<0.01$, and alcohol, $r=0.42, p<0.01$, but not cannabis $\mathrm{r}=0.02, \mathrm{p}=0.76$. Males and females did not differ on tobacco, $\mathrm{p}=0.79$, alcohol, $p=0.68$ or cannabis use, $p=0.79$. Total SOPS positive symptom scores did not significantly correlate with tobacco, $r=0.04, p=0.63$, alcohol, $r=-0.10, p=0.22$, or cannabis use, $r=0.04$, $\mathrm{p}=0.59$.

\subsection{Substance use and risk of conversion to psychosis}

Table 2 displays the number of participants receiving each of the ratings for the different substance.

When examining AUS/DUS severity ratings, converters and non-converters significantly differed in baseline alcohol use, $\mathrm{U}=1472.5, \mathrm{p}<0.01$, reflecting slightly lower use severity in converters. Groups did not differ in tobacco, $\mathrm{U}=1752.5, \mathrm{P}=0.13$, or cannabis use, $\mathrm{U}=1790.0$, $\mathrm{P}=0.19$.

The predictors of conversion to psychosis examined via Cox regression were: Baseline alcohol, tobacco and cannabis use, and age. In the final model, reduced use of alcohol was the only significant predictor of risk of conversion to psychosis, $p<0.05$. Compared to those who used alcohol, those who did not use alcohol had $2.1 \%$ higher rate of conversion to psychosis per unit time, $\mathrm{HR}=2.1, \mathrm{CI}=1.02-4.28, \mathrm{p}<0.05$. There was no association between tobacco or cannabis use at baseline and risk of conversion to psychosis. 


\section{Discussion}

This multi-site study assessed prospectively the relationship between substance use at entry into a CHR for psychosis research program and rate of conversion to psychosis. Total SOPS positive symptoms did not significantly associate with use of alcohol, tobacco or cannabis. Slightly but significantly lower alcohol use was observed in those who converted to psychosis compared to non-converters. Low levels of alcohol use were associated with an increased rate of conversion to psychosis. Neither tobacco nor cannabis use severity predicted later conversion to psychosis; suggesting use of these substances did not contribute to the rate of conversion to a psychotic disorder in this sample.

These results should be interpreted with caution. Tobacco, cannabis and alcohol use did not increase the rate of conversion to psychosis, although it is possible that high endorsement of abstinence and unimpaired substance use, and commensurately minimal prevalence of abuse in the sample may limit sensitivity to detect an effect. The negative result between increased substance use and rate of conversion to psychosis accords with conclusions of a recent review of the literature (Addington et al., in press) on substance use in CHR, and suggests that substance use may not contribute uniquely to the prediction of psychosis in people at CHR of psychosis. Alcohol use with no impairment was limited in this sample of converters and may be a proxy measure of being more sociable. It is noteworthy that the current sample was larger and therefore greater powered than Kristensen and Cadenhead's (Kristensen and Cadenhead, 2007) sample of 48 CHR subjects, who demonstrated a relation between cannabis abuse and later conversion to psychosis at 1 year, which could suggest a sensitivity of the substance use effect to sample size.

It is important to note that the current prospective study lacks information on substance use diagnoses in people at CHR of psychosis. In addition, substance use was not measured longitudinally, and therefore the results cannot address potential changes in substance use over time in this population. Interestingly, Cannon and colleagues (Cannon et al., 2008) observed evidence for a relation between increased rate of conversion to psychosis and any substance use when entered in a prediction algorithm along with four additional predictors including psychopathology and social functioning. In this regard, it may be that the importance of substance use could be through its interactive effects with other substances, symptom severity or current level of functioning. The role of substance use for risk of conversion may be better tapped by multivariate prediction algorithms incorporating multiple variables implicated in psychosis onset, such as early trauma (Bechdolf et al., 2010), genetic risk (Cannon et al., 2008) or social functional impairment (Gee and Cannon, 2011), and may be informative in future research.

\section{Acknowledgments}

This work was supported by National Institute of Mental Health grants to J. Addington (grant number U01MH066134), to D. Perkins (grant number U01MH066069), and to S. Woods (grant number U01MH066160).

\section{Role of the funding source}

The National Institute of Mental Health had no further role in study design; in the collection, analysis and interpretation of data; in the writing of the report; and in the decision to submit the paper for publication. 


\section{References}

Addington J, Case N, Saleem MM, Auther AM, Cornblatt BA, Cadenhead KS. Substance use in Clinical High Risk for psychosis - A review of the literature. Early Interv Psychiatry. in press.

Auther AM, McLaughlin D, Carrion RE, Nagachandran P, Correll CU, Cornblatt BA. Prospective study of cannabis use in adolescents at clinical high risk for psychosis: impact on conversion to psychosis and functional outcome. Psychol Med. 2012; 42(12):2485-2497. [PubMed: 22716931]

Barnett JH, Werners U, Secher SM, Hill KE, Brazil R, Masson K, Pernet DE, Kirkbride JB, Murray GK, Bullmore ET, Jones PB. Substance use in a population-based clinic sample of people with firstepisode psychosis. Br J Psychiatry. 2007; 190:515-520. [PubMed: 17541112]

Bechdolf A, Thompson A, Nelson B, Cotton S, Simmons MB, Amminger GP, Leicester S, Francey SM, McNab C, Krstev H, Sidis A, McGorry PD, Yung AR. Experience of trauma and conversion to psychosis in an ultra-high-risk (prodromal) group. Acta Psychiatr Scand. 2010; 121(5):377-384. [PubMed: 20199494]

Cannon TD, Cadenhead K, Cornblatt B, Woods SW, Addington J, Walker E, Seidman LJ, Perkins D, Tsuang M, McGlashan T, Heinssen R. Prediction of psychosis in youth at high clinical risk: a multisite longitudinal study in North America. Archives of general psychiatry. 2008; 65(1):28-37. [PubMed: 18180426]

Cooper J, Mancuso SG, Borland R, Slade T, Galletly C, Castle D. Tobacco smoking among people living with a psychotic illness: the second Australian Survey of Psychosis. Aust N Z J Psychiatry. 2012; 46(9):851-863. [PubMed: 22645396]

Corcoran CM, Kimhy D, Stanford A, Khan S, Walsh J, Thompson J, Schobel S, Harkavy-Friedman J, Goetz R, Colibazzi T, Cressman V, Malaspina D. Temporal association of cannabis use with symptoms in individuals at clinical high risk for psychosis. Schizophrenia research. 2008; 106(2-3): 286-293. [PubMed: 18809298]

Drake, RE.; Mueser, K.; McHugo, G. Clinical Rating Scales. In: Sederer, L.; Dickey, B., editors. Outcomes assessment in clinical practice. Williams and Wilkins; Baltimore: 1996. p. 113-116.

Gee DG, Cannon TD. Prediction of conversion to psychosis: review and future directions. Rev Bras Psiquiatr. 2011; 33(Suppl 2):s129-142. [PubMed: 22286564]

Korver N, Nieman DH, Becker HE, van de Fliert JR, Dingemans PH, de Haan L, Spiering M, Schmitz $\mathrm{N}$, Linszen DH. Symptomatology and neuropsychological functioning in cannabis using subjects at ultra-high risk for developing psychosis and healthy controls. Aust N Z J Psychiatry. 2010; 44(3):230-236. [PubMed: 20180725]

Kristensen K, Cadenhead KS. Cannabis abuse and risk for psychosis in a prodromal sample. Psychiatry Res. 2007; 151(1-2):151-154. [PubMed: 17383738]

McGlashan, TH.; Walsh, BC.; Woods, SW. The psychosis risk syndrome: Handbook for diagnosis and follow-up. Oxford University Press; New York, NY: 2010.

Phillips LJ, Curry C, Yung AR, Yuen HP, Adlard S, McGorry PD. Cannabis use is not associated with the development of psychosis in an 'ultra' high-risk group. Aust N Z J Psychiatry. 2002; 36(6): 800-806. [PubMed: 12406123]

Ruhrmann S, Schultze-Lutter F, Salokangas RK, Heinimaa M, Linszen D, Dingemans P, Birchwood M, Patterson P, Juckel G, Heinz A, Morrison A, Lewis S, von Reventlow HG, Klosterkotter J. Prediction of psychosis in adolescents and young adults at high risk: results from the prospective European prediction of psychosis study. Archives of general psychiatry. 2010; 67(3):241-251. [PubMed: 20194824]

Sevy S, Robinson DG, Holloway S, Alvir JM, Woerner MG, Bilder R, Goldman R, Lieberman J, Kane J. Correlates of substance misuse in patients with first-episode schizophrenia and schizoaffective disorder. Acta Psychiatr Scand. 2001; 104(5):367-374. [PubMed: 11722318]

Thompson A, Nelson B, Yung A. Predictive validity of clinical variables in the "at risk" for psychosis population: international comparison with results from the North American Prodrome Longitudinal Study. Schizophrenia research. 2011; 126(1-3):51-57. [PubMed: 21035313] 
Table 1

Demographic characteristics of the sample

\begin{tabular}{|c|c|c|c|c|}
\hline & \multicolumn{2}{|c|}{$\underline{\text { Non-converters }(n=141)}$} & \multicolumn{2}{|c|}{ Converters (n=29) } \\
\hline & Mean (SD) & Range & Mean (SD) & Range \\
\hline \multirow[t]{2}{*}{ Age } & $19.8(4.5)$ & $12.0-31.0$ & $19.7(4.6)$ & $12.3-31.2$ \\
\hline & $\mathbf{N}$ & $\%$ & $\mathbf{N}$ & $\%$ \\
\hline Gender (M:F) & $82: 59$ & 59:41 & 14:15 & $48: 52$ \\
\hline \multicolumn{5}{|l|}{ Race } \\
\hline Caucasian & 113 & 79.6 & 19 & 65.5 \\
\hline Black/African American & 13 & 9.2 & 5 & 17.2 \\
\hline Asian & 9 & 6.3 & 3 & 10.3 \\
\hline Native Hawaiian/Pacific Islander & 1 & 0.7 & 0 & 0 \\
\hline Other & 5 & 3.5 & 2 & 6.9 \\
\hline \multicolumn{5}{|l|}{ Marital status } \\
\hline Common law/Legal married & 6 & 4.2 & 2 & 6.9 \\
\hline Separated & 2 & 1.4 & 0 & 0 \\
\hline Never Married & 134 & 94.4 & 27 & 93.1 \\
\hline \multicolumn{5}{|l|}{ Education } \\
\hline Did not complete high school & 61 & 43.0 & 13 & 44.8 \\
\hline GED/High school diploma & 14 & 0.7 & 1 & 3.4 \\
\hline Some college, did not graduate & 52 & 9.9 & 3 & 10.3 \\
\hline Community college/technical degree & 5 & 36.6 & 7 & 24.1 \\
\hline College graduate & 4 & 3.5 & 2 & 6.9 \\
\hline College graduate and some Master's level courses & 3 & 2.8 & 2 & 6.9 \\
\hline Master's degree completed & 2 & 2.1 & 1 & 3.4 \\
\hline
\end{tabular}


Table 2

Rates of drug use as reported in the AUS/DUS interview at baseline ${ }^{l}$.

\begin{tabular}{|c|c|c|c|c|}
\hline \multirow[t]{2}{*}{ Baseline AUS/DUS assessment } & \multicolumn{2}{|c|}{$\begin{array}{l}\text { Non-converters } \\
\quad(n=141)\end{array}$} & \multicolumn{2}{|c|}{$\begin{array}{c}\text { Converters } \\
(\mathbf{n}=29)\end{array}$} \\
\hline & $\mathbf{N}$ & $\%$ & $\mathbf{N}$ & $\%$ \\
\hline \multicolumn{5}{|l|}{ Alcohol } \\
\hline Abstinent & 56 & 39.7 & 20 & 68.9 \\
\hline Use without impairment & 81 & 57.5 & 8 & 27.6 \\
\hline Abuse & 3 & 2.1 & 0 & 0.0 \\
\hline Dependence & 1 & 0.7 & 1 & 3.4 \\
\hline \multicolumn{5}{|l|}{ Tobacco } \\
\hline Abstinent & 94 & 67.1 & 24 & 82.8 \\
\hline Use without impairment & 43 & 30.5 & 3 & 10.4 \\
\hline Abuse & 2 & 1.4 & 1 & 3.4 \\
\hline Dependence & 2 & 1.4 & 1 & 3.4 \\
\hline \multicolumn{5}{|l|}{ Cannabis } \\
\hline Abstinent & 95 & 67.4 & 23 & 79.3 \\
\hline Use without impairment & 33 & 23.4 & 5 & 17.3 \\
\hline Abuse & 11 & 7.8 & 0 & 0.0 \\
\hline Dependence & 2 & 1.4 & 1 & 3.4 \\
\hline \multicolumn{5}{|l|}{ Cocaine } \\
\hline Abstinent & 131 & 92.3 & 28 & 96.6 \\
\hline Use without impairment & 9 & 6.3 & 1 & 3.4 \\
\hline Abuse & 0 & 0.0 & 0 & 0.0 \\
\hline Dependence & 1 & 0.7 & 0 & 0.0 \\
\hline \multicolumn{5}{|l|}{ Opiates } \\
\hline Abstinent & 139 & 97.9 & 29 & 100.0 \\
\hline Use without impairment & 0 & 0.0 & 0 & 0.0 \\
\hline Abuse & 1 & 0.7 & 0 & 0.0 \\
\hline Dependence & 1 & 0.7 & 0 & 0.0 \\
\hline \multicolumn{5}{|l|}{ PCP } \\
\hline Abstinent & 141 & 100.0 & 29 & 100.0 \\
\hline \multicolumn{5}{|l|}{ Amphetamines } \\
\hline Abstinent & 138 & 97.9 & 29 & 100.0 \\
\hline Use without impairment & 3 & 2.1 & 0 & 0.0 \\
\hline \multicolumn{5}{|l|}{ MDMA } \\
\hline Abstinent & 135 & 95.7 & 28 & 96.6 \\
\hline Use without impairment & 6 & 4.3 & 1 & 3.4 \\
\hline
\end{tabular}




\begin{tabular}{|l|c|c|c|c|}
\hline Baseline AUS/DUS assessment & $\begin{array}{c}\text { Non-converters } \\
(\mathbf{n = 1 4 1})\end{array}$ & $\begin{array}{c}\text { Converters } \\
(\mathbf{n = 2 9})\end{array}$ \\
\hline $\mathrm{GHB}^{2}$ & $\mathbf{N}$ & $\mathbf{\%}$ & $\mathbf{N}$ & $\%$ \\
Abstinent & & & & \\
Use without impairment & 139 & 98.6 & 29 & 100.0 \\
\hline Huffing & 0.7 & 0 & 0.0 \\
Abstinent & 140 & 99.3 & 29 & 100.0 \\
Use without impairment & 1 & 0.7 & 0 & 0.0 \\
\hline Hallucinogens & & & & \\
Abstinent & 128 & 90.8 & 28 & 96.6 \\
Use without impairment & 11 & 7.8 & 1 & 3.4 \\
Abuse & 2 & 1.4 & 0 & 0.0 \\
\hline Other Substances & & & & \\
Abstinent & 135 & 95.7 & 29 & 100.0 \\
Use without impairment & 6 & 4.3 & 0 & 0.0 \\
\hline
\end{tabular}

${ }^{l}$ Only ratings that were endorsed have been included in this table.

${ }^{2}$ Data was missing for one participant in the non-converter group. 